A peer reviewed open access journal indexed in NepJol; ISSN 2542-2596

Published by Molung Foundation, Kathmandu, Nepal

Article History: Received on 8 March 2021; Accepted on 25 May 2021

DOI: $\underline{\text { https://doi.org/10.3126/mef.v11i0.37849 }}$

\title{
Building Community Resilience: A Study of Gorkha Reconstruction Initiatives
}

\author{
Nirmal Chongbang ${ }^{1}$ and Devraj Bharadwaj ${ }^{2}$ \\ ${ }^{1}$ International Organization of Migration \\ ${ }^{2}$ Economic Empowerment Center
}

\begin{abstract}
Author Note
Nirmal Chongbang (iD https://orcid.org/0000-0002-9461-8164 is the provincial focal point of International Organization of Migration (UN-Migration) working in Gandaki Province, Nepal. Currently he is pursuing a doctoral degree in Social Work from Tribhuvan University, Nepal.

Devraj Bharadwaj is the lead researcher in Economic Empowerment Center, New Baneshwar, Kathmandu, Nepal. He has completed an MA English and in Sociology from Tribhuvan University.

Correspondence concerning this article should be addressed to Nirmal Chongbang. Email: nirech2005@gmail.com
\end{abstract}




\begin{abstract}
This article is based on the major findings of a field study recently conducted in Gandaki Rural Municipality of Gorkha district after the 2015 earthquake with its epicentre at Barpak of the same district, which quaked the region of northern midhills of Nepal. The study examined how far neighbouring households, community organizations, and state agencies contributed to building community resilience in this earthquake affected area. More specifically, it investigated into the efficacy of reaconstruction initiatives to provide relief to the earthquake victims for their recovery. To explore the issue, mixed-method approach of both quantitative and qualitative research was applied. Primary data were collected from the stakeholders through questionnaires and focus group discussions. The convenience sampling method was used to select 116 households from Ward No. 1 of the Municipality. The findings of the research indicate that contribution towards building community resilience was the highest from the neighbouring households followed by community organizations whereas the least contribution was from the state agencies. We found that community resilience practice in the area has not been as effective as expected. So collective and coordinated effort is necessary for building community resilience.
\end{abstract}

Keywords: community resilience, households, reconstruction, community organizations, state agencies 


\section{Building Community Resilience: A Study of Gorkha Reconstruction Initiatives}

Of the 75 districts in Nepal, 31 had been hard hit and 14 were even declared as 'crisis-hit' in 2015 earthquake in Nepal (National Planning Commission, 2015). The lives of eight million people, almost one third of the population, had been impacted in various ways by the devastating earthquake. In the context of the nationwide loss of life and property, we studied the impact of the earthquake in a small village of Makaising of Gorkha district under the Gandaki Province, which is now Ward No. 1 of Gandaki Rural Municipality as shown below.

\section{Figure 1}

\section{Makaising in Gandaki Rural Municipality}

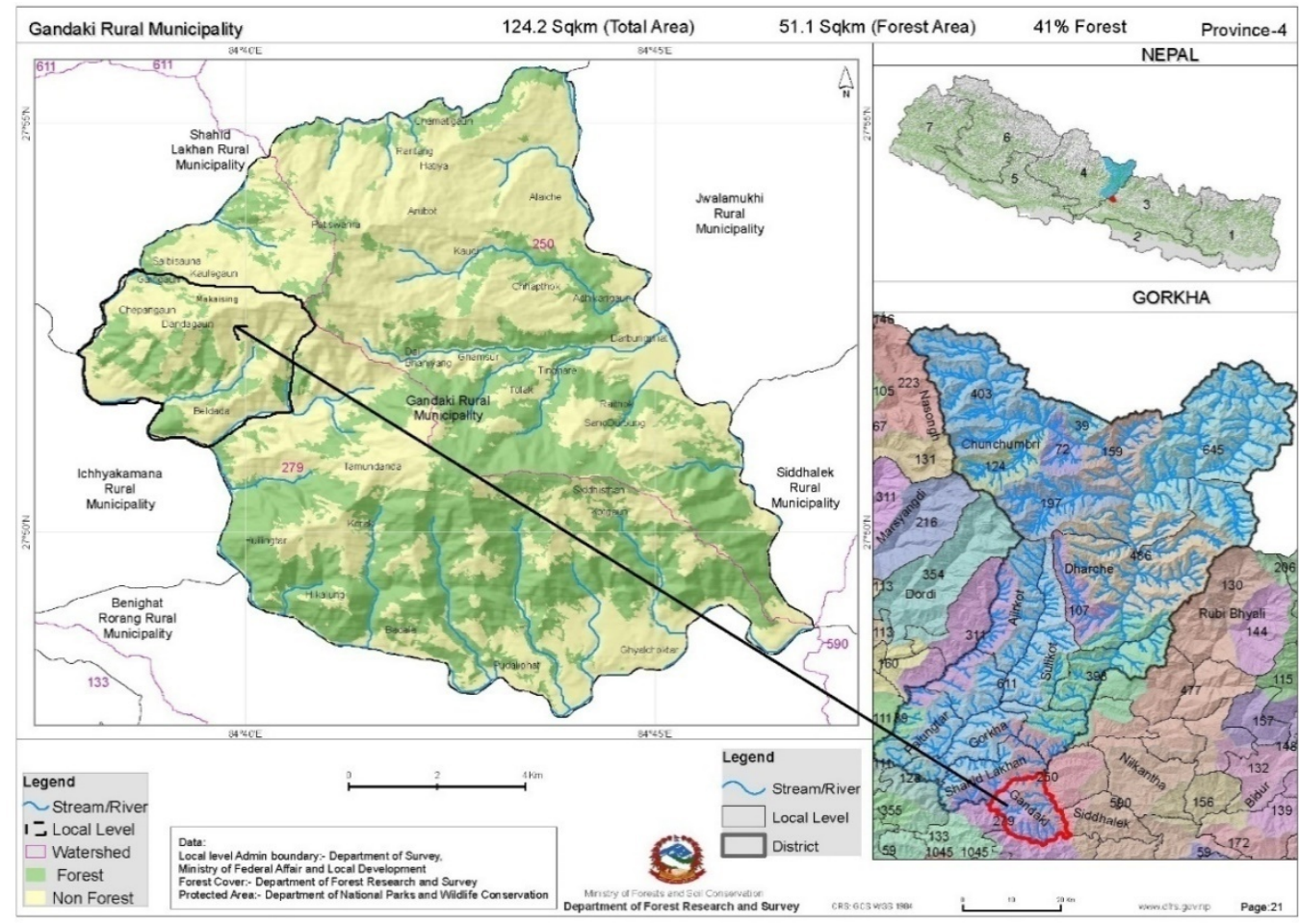

Source:

https://drive.google.com/drive/folders/1XZ8ZxHg9vs2PIbwCOeUlc94LHNXV85 1 
As a result of the big earthquake, more than 5000 households were fully damaged and nearly 600 were partially destroyed in that Rural Municipality alone. When we first met Ms. Kamala Khanal, 61 years old single woman, at Mathilo Tar, Butar of Makaising at Gandaki Rural Municipality in May 2020, she was living in her old hut alone. She was an earthquake reconstruction beneficiary but had no capacity to construct a new house due to the lack of land and proper financial condition. As we asked her about the earthquake, she said:

Due to the big earthquake almost all private and public buildings collapsed, and some highly vulnerable houses were demolished. Nearly three died and more than 20 were injured in the village. Most of the houses looked unsafe due to crack-lines that appeared in their house. Aftershocks occurred repeatedly at Makaising village. Neighbours and community people provided some kilos of rice, potatoes, and oil for kitchen purposes. After one week the government and non-governmental agencies started to distribute relief in our village with temporary shelters. I made a temporary shelter with the support of neighbours and community volunteers. I was listed as a reconstruction beneficiary in the beneficiary list of the ward office. The housing project staff and ward engineer visited my hut and explained how I could be eligible for my land and house. Project personnel and ward chairperson told me about the landless application process, required documents for the process, and took me to the ward office, prepared documents, and took me to district headquarter as well. Now I have jaggadhani purja (evidence paper) of my land ownership. I hope I can stay safe. (Khanal)

This suggests that she was terribly suffering in her hut with only small supports from neighbours, community, and ward office. The support from the government and development agencies had not yet been adequately provided. 
In the aftermath of the earthquake, the Municipality tried to recover with the cooperation of development partners and donor agencies. They were jointly engaged in housing, community building, school, health, and cultural heritage reconstruction. The Government of Nepal [GoN] also initiated Gorkha quake reconstruction through National Reconstruction Authority [NRA], which is now the overall lead and coordinating body for reconstruction and recovery throughout the nation in this regard.

In order to reconstruct and build resilience after the disaster, every recovery and reconstruction initiative should be safe. The concept of building a safe and resilient community was initiated by the Sendai Framework for Disaster Risk Reduction [SFDRR] in 2015 and accepted by the GoN. This is a globally accepted framework which assumes that the government builds a resilient community with the joint investment of public and private partnership investment regarding the disaster management. Resilience building can be done through both structural and non-structural measures. According to the International Federation of Red Cross and Red Crescent Society (IFRC, n.d.), “This is essential to enhance the economic, social, physical, and cultural resilience of persons, communities, countries, and their assets as well as the environment" (p. 6).

Reconstruction initiatives can contribute to building safe community resilience and building back in a better way. It can become a way of generating hope for a safe community, reducing future vulnerability, and economic losses. Trained construction workers, conscious house owners, and accountable state agencies can contribute to safe and resilient reconstruction. The building back better approach follows the building code of rural municipality and constructs houses based on the pre-designed outlook of NRA. Households, communities, ward authority, rural municipality level reconstruction committee, and other state agencies are major factors that can regularly contribute to the reconstruction from disaster damage. It is in this context that we have conducted a field based research 
in Ward No. 1 of Gandaki Rural Municipality (previously Makaising Village Development Committee). We wanted to know the effectiveness of reconstruction intitiaves that were launched in the area and to what extent they could provide relief to the earthquake victims.

\section{Conceptual Background}

The term 'resilience' was initially used to define the capacity of a material to spring back to the original shape or to return to the previous balance after a displacement. Bodin and Wiman (2004) "With respect to stability in terms of elasticity -in technology commonly also referred to as resilience - we note that the faster the system returns to its equilibrium after a displacement, irrespective of whether no, few, or many oscillations are involved, the more elastic (resilient) it is. The importance of resilience in several cases outweighs that of other stability aspects; for instance, the temporal response of a shock absorber is more important a property to consider than the actual position of its stability (equilibrium) point" (pp. 3-4).

Schipper (2016) defines resilience framework emphasizing on what resilience is or how to achieve it but the reason that resilience needs to be built in the first place is the shocks and changes that jolt existing systems. She explains what effects these shocks and changes have and what can be done to ensure that those effects are minimized or eliminated through collective engagement. She further argues that an approach should ideally be complemented by an analysis of root causes of vulnerability since taking a hazardous perspective also requires an understanding of all the components of vulnerability analysis.

The idea of community resilience develops from the concept of resilience but is further complex by the difference in the meaning of community. Just as resilience can be used to mean recovery capacity of an individual from difficulty, so it can also be applied to the community as a whole. Communities are the common frame of social and financial situations that affect one another 
collectively in composite ways. The contemporary understanding of community resilience is the collective sense of stress, adaptation, wellness, and resource dynamics. It is a method of connecting a supportive system of adoptive capacities to the adaptation after a disaster strike. The available literatures state that financial progress, social resource, communication and community capability together contribute to build community resilience. The post-disaster community resilience is an evaluation of the past and existing work that builds the collective capacity such as social support system. Here we use the term "community resilience" to mean planning and preparedness for disaster response.

Disasters are both natural calamities and man-made hazards. They are becoming more aggressive and very expensive to rehabilitate. They have reflected increasing global economic losses over the years. Natural hazard becomes devastating due to our poor preparedness and low capacity. McFarlane and Norris (2006) define "disaster as a potentially traumatic event that is collectively experienced, has an acute onset, and is time-delimited; disasters may be attributed to natural, technological, or human causes" (p. 4). This description includes unexpected natural disasters such as earthquake. It also includes the disaster induced adverse conditions.

Reconstruction refers to the construction of physical infrastructures that have been damaged by the natural calamities. Destruction caused by the disasters is the result of our low preparedness or lack of it and the inadequate setting of the development. The disaster is the outcome of both human activities and natural phenomena that involve the conditions of risk and vulnerability.

Michaels et al. (2019) try to explain the stakeholders' engagement in reconstruction process for resilience building. They raise major issues regarding stakeholder's engagement in reconstruction based on evidence, a gap identified through evidence-based mapping on resilience practices in reconstruction. Safe and resilient house building is possible when all stakeholders are engaged 
thoroughly right from the site selection of construction, when house owners understand their house layout and map, and when the state agencies provide regular technical and social support in reconstruction. Safe, low loss guaranteed, durable and multiple hazards risk-sensitive reconstruction can be considered as resilient reconstruction.

Community-based reconstruction practices are those practices which are based on their need, choice, and capacity. They can contribute to the households and their community-based structures for safe resilience building. Based on their antcipated capacity the households can foresee their possible risk and prepare for future risk reduction, which may make a significant difference in their lives and livelihoods. Coady et al. (2004, as cited in Akinola, 2017) in this connection argue, "However, targeting in many low and low-middle income countries are sometimes done using community-based targeting methods and mechanisms (CBTMs), which allow community members to participate in the implementation of social protection programs. Yet, while community-based targeting as a method simply refers to the involvement of community organizations, authorities, or agents, such as local leaders, civil society, or non-governmental organizations, in the selection of beneficiaries of social protection programs" (p. 2).

Regmi et al. (2019) explain that the practice of disaster risk management and adaptation to climate change focuses on reducing vulnerability and increasing towards stresses and adverse impacts of climate change exposure as well as vulnerability and increases resilience to the potential adverse impacts of climate extremes and stresses. In the context of Nepal, the theme of building resilience has been practiced in many areas of development. Intervention including disaster risk reduction, climate change adaptation, and livelihood interventions are the major ones.

Reconstruction and resiliencience are different concepts but they are interconnected also. When we intervene, reconstruction initiates. When we 
reconstruct, resilience is built. But the resisilience should be safe and sustainable. For sustaninable resilience social support is necessary. Sustainability is the broader category, where resilience is a crucial component. If reconstruction only emphasizes on building back better in terms of physical terms, then social supporting culture can be left out. Hence, it is essential to bring together social support culture with reconstruction efforts for building community resilience.

The available literature stated above shows that researchers so far have mainly studied structure-based resilience approaches and explored the chain perspective of resilience. They have described service delivery initiatives to build resilience but have not adequately studied the collective contribution of individual households, community organizations, and state agencies for building resilience. We have seen that the previous researchers and writers have not satisfactorily raised their concern about social aspects that are also equally import for building community resilience. Therefore, we have examined how the local households can contribute to building resilience with the support of community organizations as well as state agencies as a collective enterprise. This study provides useful insights to our better understanding of community resilience. It is on this ground that we tried to seek answers to such questions as how local households, community organizations, and state agencies' initiatives can contribute to building resilience through reconstruction initiatives, how they can support themselves, and how they make themselves resilient.

\section{Methodology}

As mentioned earlier, the mixed-method approach of both quantitative and qualitative research is applied to collect and interpret the data making more use of the quantitative method. Creswell (2014) explains that mixed methods are useful to seek convergence across qualitative and quantitative methods. We have applied his concept in this research. 
All households who were engaged in reconstruction from Ward No. 1 of the Gandaki Rural Municipality were identified as beneficiaries in coordination of Ward Office, Government of India- Nepal Houseing Reconstruction Project (GoINHRP) project site office and NRA engineer. Out of these, 116 households were sampled purposively from Makaising, Lamagau, Chepanggau, and Butar. These households are reconstruction beneficiaries who are receiving tranche, amount of cash support from GoN-NRA, to build their houses in the aftermath of the Gorkha earthquake 2015.

The sources of primary data are field observation, personal interviews, Focus Group Discussions (FGD) in different groups, and Key Informant Survey (KIS) of the community representatives. A structured questionnaire was used on household based data collection which was close-ended, and semi-structured questionnaire surveys were conducted in community-based group discussions in their meetings. These data were analyzed through triangulation for quality control. Checklists were applied during the ward office visit. Tally was done with citizen charter board and service delivery checklist on reconstruction. The questionnaires were applied for data collection among the households, community organization members, and selective key informers. Diferent official records and documents, available in e-resources such as national and international research and publication were used in literature review.

This study is chiefly based on primary data. We have taken interviews from households, community-based organization members, and ward authority. KIS and FGD were used to generate the data for triangulation. The practice of descriptive and analytical methods were applied for analysing the data.

Views of reconstruction beneficiaries have been analyzed in terms of Likert (1-5) scale. This is based on the opinions of households, community organizations, and ward authority supports. The expected intensity of an individual understanding has been rated in a line of spectrum starting from the 
agreement or disagreement. This 5-point scale has been useful to measure their experiences, understandings, and opinions. This scale was used to express an individual's perception in degree, where 1 is for 'strongly disagreed', 2 for 'disagreed', 3 for 'undecided', 4 for 'agreed', and 5 for 'strongly agreed'. In addition, we have applied Cronbach alpha method for significant tests. This is mostly used for assessing internal consistency of the questionnaires. In this study we have used this metod to asset it.

\section{Results and Discussions}

According to Ministry of Home Affairs (2019), "Nepal is one of the most disaster-prone countries affected by recurrent multiple hazards. Every year, the country suffers from the great loss of human lives and damage of properties due to natural and human caused disasters such as earthquake, flood, landslide, thunderbolt, fire, road accident, and epidemic" (p. 11).

Disasters can affect a socio-economic status of individuals and communities. In the study area the low employment status, rare financial services access, and weak institutional preparedness had negative effects on the households during disaster and recovery period. Household capacity can contribute to better response and recovery. The term capacity means the ability of individuals, households, and communities to absorb, adapt and recover from shocks and their stresses. We focused our study on the effects of earthquake, reconstruction processes, and resilience practices among the households, community organizations, and state agencies and organized our major findings in the following paragraphs.

During the study, we found economic, social, and cultural diversity settlements at Makaising. The different communities such as Gurung, Adhikari Brahmans, Chepang and Magar comprise a significant share of the population in this area. They have practiced social support on reconstruction, especially on labor and material support. Different community-based institutions like the 
community forest user committee, mother groups and farmers' groups had supported the earthquake-affected households.

\section{Contribution of Local Households}

Households and communities have potential of playing effective roles to help recovery of the disaster victims and enable them to adjust in the aftermath of the disaster. The the disaster victims are the reconstruction beneficiaries who can be well supported from local households who are not affected by the the disaster. The household experiences and their practices are one of the major sources of our study in the village of Makaising. We studied the condition of community resilience practices based on their individual experiences and socio-cultural setting. Supporting culture and maintaining a good relationship is in practice in the study area, which has contributed to building community resilience.

The socio-economic status of the household is based on their production, earnings, and saving capacity. The employment rate of the study area is only 9.49\%. Among those who are employed, 36.35\% are migrant workers, $18.18 \%$ are in NGOs, $18.18 \%$ are in others, and $9.09 \%$ are in government jobs. Only $9.48 \%$ population (11 respondents) shared that they can survive on their own earning. Only $15.51 \%$ (18 respondents) survive more than nine months, $32.75 \%$ (38 responders) can survive more than six months, $24.41 \%$ (26 respondents) can survive more than three months and $19.82 \%$ (23 respondents) shared that they can survive around three months on their own income. The statistics shows that due to the low employment rate and low self-employment practices, households are struggling for living and saving for the future. The households can improve their economic status being engaged in self-sustained agricultural enterprises such as easily marketable cash crops, vegetable farming, livestock pultry farming etc. They can do it more comfortably with the help of community financial organizations such as cooperatives, forests groups, women's support groups etc. The financial status and the household capacity is shown in Table 1 below. 
Table 1

Financial Status and Capacity of Households

\begin{tabular}{|c|c|c|c|c|c|c|}
\hline S.N. & Source of income & Male & Percent & Female & Percent & $\begin{array}{l}\text { Total } \\
\text { Percent }\end{array}$ \\
\hline 1 & $\begin{array}{l}\text { Formal employment } \\
\text { opportunity }\end{array}$ & 10 & 8.62 & 1 & 0.86 & 9.49 \\
\hline 2 & $\begin{array}{l}\text { Self-earning } \\
\text { (sufficiency to living } \\
\text { through earning) }\end{array}$ & 17 & 14.65 & 3 & 2.58 & 17.24 \\
\hline 3 & Saving income & 10 & 8.62 & 1 & 0.86 & 9.48 \\
\hline 4 & $\begin{array}{l}\text { Is there any } \\
\text { engagement into } \\
\text { local saving group }\end{array}$ & 5 & 4.31 & 14 & 12.06 & 16.37 \\
\hline 5 & $\begin{array}{l}\text { Did you get local } \\
\text { authority helps } \\
\text { during crises }\end{array}$ & 19 & $\begin{array}{l}16 \\
.37\end{array}$ & 8 & 6.89 & 23.27 \\
\hline 6 & $\begin{array}{l}\text { Did you get any } \\
\text { other } \\
\text { formal/informal } \\
\text { supporting } \\
\text { mechanism while } \\
\text { crises strike? }\end{array}$ & 17 & 14.66 & 11 & 9.48 & 24.19 \\
\hline & Total & 78 & 67.25 & 38 & 32.75 & 100 \\
\hline
\end{tabular}

Source: Field survey, 2020

This data shows the source of information about household's self-defined resilience capacity which seems an important indicator of the household's response capacity. It indicates that only $17.24 \%$ of the total households sufficiently live on their earnings. Respondents shared that the traditional 
agricultural systems do not address daily household needs. Only $9.49 \%$ have formal employment opportunities at the local level and $9.48 \%$ of respondents saved a samall part of their income. The data also shows that more than $90 \%$ of the respondents cannot save their earnings. Lack of sufficient employment and self-entrepreneurship opportunities at the local level unfold the poor saving capacity of the households. The remarkably low amount of saving has affected the socio-economic status of the households, which has further impacted on supporting capacity to the victims during the earthquake disaster. A household earning and the sufficiency of living on their earning rate are lower (17.24\%). At the local level, earning environment is poor; households cannot produce sufficiently due to unfavorable weather for farming, inadequate irrigation system, and limited fertile land. Due to the low production of local products households have a low chance of earning. Due to low earning, they cannot manage savings without which they cannot offer to support another household either in normal times or during the crises. The result thus indicates that households and community members have their own formal/ informal support mechanism as the prime source for building resilience.

Local formal and informal support practices have also supported the households during the disasters, which covered the largest percentage of the household responses $(24.19 \%)$. The study also shows the first respondent to disaster is the nearest household and community-based organizations and their members. Thus, we need to invest in the scale-up capacities of households for further building resilient communities. Household capacity can be enhanced through production support, earning, and saving. Higher saving capacities of households can contribute to future supporting mechanisms in disaster management. They need to emphasize local production, self-entrepreneurship, high earning, and high saving. Having high earnings and savings, households can invest in further support to needy households during the disaster crisis and can 
contribute more in response to the disasters for recovery. Despite low earnings and savings the local households have the highest degree for contribution to the the earthquake victims. Had they had handsome savings, they could have done more to help the victims. Further, their social-cultural traditions have also contributed to some extent.

\section{Contribution of Community Organizations}

Households have received support in disaster response, recovery. and reconstruction from community organizations. Some community organizations have supported house reconstruction. The local/community-based organizations like local mothers' groups, forest user groups, and saving and credit groups have supported their members. The local forest user committees supported individuals with wood and firewood while they made temporary shelters. Table 2 is the response of household on how community organizations contributed to their relief and recovery.

\section{Table 2}

Households' Perceptions on Contribution of Community Organizations

\begin{tabular}{lllllll}
\hline $\begin{array}{l}\text { S. } \\
\text { N. }\end{array}$ & $\begin{array}{l}\text { Social support } \\
\text { during the crisis }\end{array}$ & Male & Percent & Female & Percent & $\begin{array}{l}\text { Total } \\
\text { percentage }\end{array}$ \\
\hline 1 & Strongly disagreed & 6 & 5.17 & 5 & 4.31 & 9.48 \\
2 & Disagreed & 5 & 4.31 & 7 & 6.03 & 10.34 \\
3 & Undecided & 7 & 6.03 & 8 & 6.90 & 12.93 \\
4 & Agreed & 22 & 18.97 & 16 & 13.79 & 32.76 \\
5 & Strongly Agreed & 22 & 18.97 & 18 & 15.52 & 34.48 \\
\hline & Total & 62 & 53.45 & 54 & 46.55 & 100 \\
\hline
\end{tabular}

Source: Field survey, 2020

$34.48 \%$ of respondents said that the local groups have a crucial role in resilience building. They further added that local mothers' and farmers' groups supported their member's households. The local saving and credit groups 
considered low-interest loans to member households to help them start up their own business. After getting a soft loan, members of such committees already started vegetable farming, livestock rearing, and poultry farming. Among the total respondents $38.48 \%$ of respondents agreed that community organizations have contributed to building resilience. The second-largest group respondents $32.76 \%$ accepted the same, followed by the third-group of respondents $12.93 \%$ who were undecided. The fourth group of $10.34 \%$ disagreed, and $9.48 \%$ strongly disagreed.

During the FGD events, respondents shared that the local community organizations have their own rules and policies for the meeting, institution operation, saving, and credit mobilization. Most of the local groups have their resources in both cash and kind based on their monthly saving, forest-based resources at forest users' groups, and own seed banks in traditional in farmers' groups. They were supported by their members during the crisis. Farmers' group provided seeds, mothers' group supplied small loan, and a forest user group provided firewood or furniture. This support from community organizational support system was based on collective actions. They were engaged in earning, saving, and re-distribution while their member households were in crisis.

The respondents of the FGD evenets also mentioned that the local groups such as neighbours, mothers' groups, farmers' groups, tole associations, and saving and credit groups supported the households and communities through ready response to reconstruction in their communities. Respondents shared that they had exemplary support systems for construction in practice. An example is Parma system where human resources were exchanged in construction works. With the support of community members community volunteers and a trained mason seven houses were constructed in this area. During the Parma, the person whose house was being constructed managed day meal/ snacks; otherwise community members managed the meals themselves and helped. This suggests 
that the community organizations also contributed to building community resilience despite in smaller degree than that of local households.

\section{Contribution of State Agencies}

According to NRA guidelines the household received 300,000 Nepalese currency based on three installments. The ward authority was closely facilitating overall reconstruction. Facilitation started from beneficiary registration and recommendation to NRA through District-Level Project Implement Unit (DLPIU). After the formal agreement eligible beneficiaries received their first tranche $(50,000 \mathrm{NRs})$ from the nearest bank and they had to do a Damp Proof Course (DPC) of house. After the completion of DPC, they could proceed for a second installment (150,000 NRs) and when they completed their roof level, they were eligible for a third tranche (remaining 50,000 NRs). In this whole service facility system, a technical person desginated by the ward authority regularly visited the beneficiary's house and provided technical support to a trained mason and the houseowner free of cost for the construction work.

\section{Table 3}

Households' Responses to the Support of State Agencies

\begin{tabular}{lllllll}
\hline S.N. & $\begin{array}{l}\text { State agency } \\
\text { support }\end{array}$ & Male & Percent & Female & Percent & $\begin{array}{l}\text { Total } \\
\text { Percentage }\end{array}$ \\
\hline 1 & Strongly agreed & 31.00 & 26.72 & 11.00 & 9.48 & 36.21 \\
2 & Agreed & 10.00 & 8.62 & 9.00 & 7.76 & 16.38 \\
3 & Undecided & 16.00 & 13.79 & 11.00 & 9.48 & 23.28 \\
4 & Disagreed & 11.00 & 9.48 & 11.00 & 9.48 & 18.97 \\
5 & Strongly & & & & & \\
& disagreed & 2.00 & 1.72 & 4.00 & 3.45 & 5.17 \\
\hline \multirow{2}{*}{} & Total & 70.00 & 60.34 & 46.00 & 39.66 & 100 \\
\hline
\end{tabular}

Source: Field survey, 2020. 
Table 3 shows the response towards the contribution of state agencies to building community resilience. The Likert scale result indicates that $36.21 \%$ were strongly agreed, followed by $16.38 \%$ who agreed, $23.23 \%$ were undecided, $18.97 \%$ disagreed. and $5.17 \%$ strongly disagreed on the contribution of state agencies to resilience building.

Households expected prompt delivery services from the ward authority during the disaster crisis. They were satisfied with ward service and support on reconstruction. The ward authority provided reconstruction services including the identified probable reconstruction beneficiary, the beneficiary registration process, coordination, and recommendation to NRA. The landless and vulnerable houses were verified based on NRA guidelines, recommended to the Rural Municipality and NRA if found eligible, and supported by the state agencies in reconstruction.

During the FGD events at Makaising, Mr. Chij Bahadur Damai, 56 year old man, shared his happiness with this research team member on how halted house is constructed with the support of neighbors, community people, and state agencies. He explained further:

I was staying single in Gandaki Rural Municipality Ward No. one, at Makaising. After the collapse of my house in the earthquake in 2015, I was listed as a reconstruction beneficiary and got the first tranche. I spent some amount of the first tranche on purchase for Dasain festival celebration and hardly did DPC for house construction. After completion of the first DPC, I was eligible for a second tranche, but unfortunately, my son took away all the amount of the second tranche budget so I could not start my story. My neighbours, relatives, community people, and ward authority were collectively engaged in my house construction and finally and now I am to live in my own house. 
Considering the mixed responses of the household respondenets we can understand that the state agencies also contributed signifaicantly though further smaller degree than the community organizations.

\section{Analysis and Interpretation}

In order to make the findings of our study reliable and trustworthy, we used Cronbach's alpha in all three sectors as stated above. This scale can be used for analyzing validity and reliability. The impact of the support practices of the local households, community organizations, and state agencies could contribute to building resilience in the study area. It is based on the accuracy and exactness of measurement that represents sampling procedures. The Cronbach alpha provides a coefficient of inter-item correlations that measures the internal consistency among the items. The statistics below shows our assessment of the contribution based on the measurement by using the following formula in Table 4:

\section{Table 4}

The Use of Cronbach's Alpha for Assessment

Let us imagine that the number of items in the survey is five, then the computed average correlation is 0.592

Therefore, alpha $=$ nrii $/ 1+(\mathrm{n}-1)$ rii

$=5(0.592) / 1+(5-1) 0.592$

$=2.96 / 3.368$

$=0.87$

The computed alpha ranges from 0.60 to 0.90 and characterized to:

1. More than 0.90 very highly reliable

2. From 0.80 to 0.90 highly reliable

3. From 0.70 to 0.79 reliable

4. From 0.60 to 0.69 marginally/minimally reliable

5. Below than 0.60 unacceptably low reliability 
Table 4 shows the computed result of Cronbach alpha fomula used for reliability assessment. The standardized value of 0.87 is less than the table value (0.90). This provides us with an overall reliability coefficient for a set of variables (e.g., questions). Therefore, the validity analysis of the practices contributing to building resilience shows high reliability. In the case of this study this formula helped us to understand the degree of different supporting agencies for building community resilience.

\section{Conclusion and Recommendations}

Based on the things stated above, we can conclude that this study is primarily focused on the relationship between the reconstruction supporting agencies and the community resilience. It shows how the local households, community organizations, and state agencies separately and together have contributed to building community resilience.

Despite in different degrees, all three components have contributed to community resilience building through reconstruction in Gorkha. The local households tried to build their capacity through their own earnings and savings. The community-based organizations supported their members based on their common assets. The state authorities also supported the earthquake affected households based on their reconstruction package and by formulating further reconstruction plans and budget allocation.

This study investigated the high earning-saving capacity of the local households. House to house supporting practices in reconstruction are highly remarkable. Local households supported to one another through their savings, available assets, and by exchanging human resources. The households could add their earning and saving capacity through their investment and selfentrepreneurship.

The community-based organizations supported their members through delivery of soft loans from financial groups, supply of forest products such as 
wood for house construction and furnishing. Some local group members were also engaged in building houses as volunteer masons. Social bonding practices of community organizations helped the disaster victims. Community organizations could enhance their capacity to support by collective entrepreneurship.

The state agencies also supported recovery process from the annual plan and budget allocation, technical support on the house construction, and tranche facilitation to an eligible household. They also provided certificates to the landless households, facilitated land purchasing, collected social support for house construction of the landless and single woman households. This indicates that only a well-planned and high equipped allocation of resources from local authority can contribute to building resilience.

The paper thus indicates the degree of contribution of local households, community organizations, and ward authority to building community resilience. We have tried to investigate underlying factors of household capacity (building of household), community-based organizations, and state agencies which contribute to building resilience. Although efforts to build community resilience in the area achieved only limited success due to the uncoordinated reconstruction initiatives of the benefactors, the local households, community organizations, and the state agencies can achieve grater success through systematic, coordinated, and collective actions for building community resilience in the future.

This research did not consider other factors which would contribute to building community resilience, for instance, forecasting, absorptive, adaptive, and transformative capacities of households and communities. The study area was limited to one ward of Gandaki Rural Municipality at Gorkha, which might not represent the experiences of resilience-building at different places in earthquake affected communities of Nepal. This study can nevertheless be considered as a baseline for further studies of community resilience building. Future researchers can explore the things that we have not considered in this study. 
We recommend that formulation of appropriate risk recovery policy can scale up the capacity of community-based organizations to address the future risks. It is essential to formulate both short term quick recovery management policy as well long-term policies and programs to build an integrated disaster risk management system that would be in line with social protection policies and development integration policies among the local authorities which can contribute to building community resilience. It is hoped that this study helps to formulate appropriate policies regarding the community resilience buidling practices. 


\section{References}

Akinola, O. (2017, June 12). Governing social protection in developing countries through Community-Based targeting mechanisms: A case study of Nigeria's "In care of the people" conditional cash transfer programme. ODRC-CRDI, Canada. https://idl-bnc-idrc.dspacedirect.org/handle/10625/56390

Bodin, P., \& Wiman, B. L. B. (2004, January). Resilience and other stability concepts in ecology: Notes on their origin, validity, and usefulness. www.researchgate.net. https://www.researchgate.net/publication/236208772

Creswell, J. W. (2021). Research design: Qualitative, quantitative and mixed methods approaches (4th ed.). SAGE Publications, Inc. https://study.sagepub.com/creswellrd4e

National Planning Commission. (2015). Post disaster needs assessment report. Government of Nepal. https://www.npc.gov.np

Mcfarlane, A. C., \& Norris, F. H. (2006). Definitions and Concepts in Disaster Research. In F. H. Norris, S. Galea, M. J. Friedman, \& P. J. Watson (Eds.), Methods for disaster mental health research (Revised ed., pp. 3-6). Guilford Publications. https://www.guilford.com/excerpts/norris.pdf

Michaels, L., Baniya, J., \& Ahmed, N. (2019, March 27). Reconstruction Research in Nepal, Strengthening Resilience and Response to Crises. IMC worldwide.

https://assets.publishing.service.gov.uk/media/5d285927ed915d69895f31c7/

DFID_Reconstruction_Research_Final_Report_10.07.2019.pdf

Regmi, B. R., Watkiss, P., Gentle, P., \& Bhandari, D. (2019, April 7). From risk to resilience: An integrated approach to harmonize climate change and disaster risk planning (No. 3122495). Oxford Policy Management Limited. https://www.opml.co.uk/files/Publications 
Schipper, L. (2016, April 21). Defining a resilience approach for CARE international. www.researchgate.net/publication. https://doi.org/10.13140/RG.2.2.11935.15524

International Federation of Red Cross and Red Crescent Society. (n.d.) Sendai framework for disaster risk reduction, 2015-2030. https://media.ifrc.org/ifrc/. https://www.ifrc.org/docs/IDRL/Sendai_Framework_for_Disaster_Risk_Red uction_2015-2030.pdf

Ministry of Home Affairs. (2019, February 12). National policy for disaster risk reduction. The Government of Nepal. http://drrportal.gov.np. http://drrportal.gov.np/uploads/document/1476.pdf 